\title{
Filosofía política y Teoría del Derecho (filo- sofía del lenguaje, lingüística y teoría de la argumentación). Tomás de Aquino en diálogo con Bobbio, Rawls, Chomsky y Alexy *
}

\section{Political Philosophy and Theory of the Law. Thomas Aquinas in Dialogue with Bobbio, Rawls, Chomsky and Alexy}

\author{
Carlos Alberto Cárdenas Sierra \\ Édgar Antonio Guarín Ramírez **
}

Fecha de recepción: 1 de agosto de 2008

Fecha de aprobación: 18 de septiembre de 2008

\section{Resumen}

El presente artículo corresponde a una muestra del resultado de la investigación acerca de la posibilidad del diálogo entre la filosofía política y jurídica de Tomás de Aquino con la filosofía política y jurídica transnacional contemporánea más influyente en Colombia. En esta oportunidad se escogió para el encuentro con el Aquinate a los siguientes autores: Norberto Bobbio, John Rawls, Noam Chomsky y Robert Alexy.

\section{Palabras clave}

Tomás de Aquino, bien común, persona, prudencia política; Norberto Bobbio, acción social, acción política, poder político, fuerza política; John Rawls: justicia como imparcialidad, utopía realista, sociedad de Ios pueblos; Noam Chomsky: gramática universal, gramática generativa, libertad; Robert Alexy: código de razón práctica, argumentación racional, fundamento del discurso.

Corresponde al título del resultado de la investigación que pertenece a la línea institucional: Pensamiento Práctico de Tomás de Aquino en diálogo con el pensamiento práctico contemporáneo.

** Docentes investigadores adscritos al Centro de Investigaciones Socio-jurídicas Francisco de Vitoria de la Facultad de Derecho de la Universidad Santo Tomás; y miembros del Grupo de Investigación Raimundo de Peñafort clasificado categoría A por Colciencias (2006-2009). Correo electrónico: torreondomingo@hotmail.com 


\section{Abstract}

The present article corresponds to a sample of the result of the investigation about the possibility of dialogue between political and juridical philosophy of Thomas Aquinas with the transnational contemporary political and juridical philosophy that is most influent in Colombia. In this opportunity for the encounter with the Aquinate, the following authors were chosen: Norberto Bobbio, John Rawls, Noam Chomsky and Robert Alexy.

\section{Key words}

Thomas Aquinas, common wealth, political prudence, Norberto Bobbio, social action, political action, political power, political force, John Rawls : justice as impartiality, realistic utopia, society of peoples, Noam Chomsky: universal grammar, generative grammar, freedom, Robert Alexy: practical reason code, rational argumentation, discourse fundament.

\section{INTRODUCCIÓN}

Cuando se delimitó el objeto de investigación, se encararon dos problemas: ¿cuáles serían los criterios de selección de los autores?, y ¿cuáles eran el punto de partida y el punto de encuentro del diálogo entre Tomás de Aquino y los contemporáneos?

\section{Criterios de selección de los autores}

Después de deliberar en el seno del equipo de investigación, Raimundo de Peñafort, se decidió que los criterios serían cinco:

- Recepción en la Facultad de Derecho de la Universidad Santo Tomás, especialmente a través de la asignatura de Analítica'.

- Encuentros académicos en Colombia por parte de los autores en proceso de selección.

- Grado de recepción en nuestro medio e influjo en nuestros esquemas de comprensión o en la doctrina.

1 La asignatura de Analítica es un espacio lectivo-investigativo de la Facultad de Derecho de la Universidad Santo Tomás. En este espacio los estudiantes, guiados por los docentes, se acercan a las fuentes primarias del pensamiento (filosofía, política, economía, sociología, etc.) que orientan los discursos de las demás asignaturas, cuyo objeto es el aspecto del derecho como ciencia. La analítica no es cátedra, como las demás asignaturas, es trabajo lectivo-investigativo propio del estudiante.
- Posibilidad de relacionar a los autores, convertidos en "Colegio intelectual", en torno a análogas preocupaciones contemporáneas, tras una prelectura prima facie.

- Posibilidad de relacionar esas preocupaciones con intereses análogos de Tomás de Aquino en su contexto histórico.

Se ajustaron al primer criterio: John Rawls, de quien se viene leyendo la Teoría de la justicia desde 2003, y Robert Alexy, de quien se ha leído, entre 1996 y 1999, su Teoría de la argumentación jurídica. El segundo criterio permitió tener en cuenta a dos autores más: Noam Chomsky, quien visitó Colombia en 2003, y Norberto Bobbio, quien lo hizo en la década del ochenta. Alexy también visitó nuestro país en 1994.

El criterio de la visita tiene por finalidad evidenciar dos aspectos justificativos: interés por los problemas latinoamericanos o interés por los problemas colombianos. En el caso de Chomsky, por sus escritos de filosofía política dedicados a América Latina y el Caribe, se sabe que se ha interesado por los dos. Bobbio también escribió, pero, especialmente, en torno a problemas latinoamericanos globales. De Alexy se pudo establecer, a partir de su visita a la Universidad Externado de Colombia, su interés por el análisis crítico de la sociedad latinoamericana 
y la intención de precisar aspectos de la Teoría de la argumentación, que pueden servir a los operadores jurídicos latinoamericanos para iluminar sus decisiones.

El tercer criterio permitió establecer la pertinencia de Alexy, Bobbio, Chomsky y Rawls. Este último cumple con el primer criterio, pero no con el segundo, $y$ resulta de enorme peso desde el punto de vista del tercero. De hecho, se encontró que la Corte Constitucional colombiana ha fundamentado fallos con base en la perspectiva rawlsiana. De igual forma, se evidenció que Rawls es uno de los autores más comentados en nuestra lengua en los ámbitos de la Filosofía, el Derecho, la Sociología, la Economía, la Ciencia Política, etc. Aunque Rawls nunca vino a nuestro país, su voz sigue presente en nuestras aulas, en nuestros tribunales y se ha convertido en amplificadora de la voz de muchos intelectuales de habla española, que lo consideran su "autoridad" preferida.

El cuarto criterio llevó a descubrir entre los autores, a pesar de no pertenecer a las mismas corrientes ideológicas, una afinidad espiritual en torno a los problemas centrales de nuestra época: la urgencia de la justicia, de la democracia crítica y de las condiciones de la comunicación ético-política constructiva. Esta convergencia llevó a considerarlos miembros de una "colegiatura intelectual", que está motivada por la angustia de la humanidad, necesitada de lucidez frente a la falta de rumbos compartidos y de valores con suficiente poder de atracción, tras el derrumbe de las antiguas seguridades racionales. El quinto criterio obligó repensar la cosmovisión del gran maestro medieval, tratando de descubrir cuanto sugería a sus contemporáneos y a sus discípulos de distintas épocas; así, se pudo calibrar el grado de afinamiento del tomismo vivo, válido interlocutor de quienes se interesan de nuevo por dimensiones que el Aquinate consideró esenciales en la construcción social y política para alcanzar "la vida buena".

\section{Punto de partida y el punto de encuentro del diálogo con Tomás de Aquino}

El punto de encuentro ya está dado por el objeto de la investigación: filosofía política y filosofía del derecho. Lo que no se tenía claro era el punto de partida, es decir, ¿qué es lo que hace posible el diálogo entre un hombre del siglo XIII con hombres del siglo XX y XXI?

El hecho real de que se trate de un hombre del siglo XIII en diálogo con hombres de los siglos XX y XXI ya puede acercar a la respuesta sobre el punto de partida. Si como dice Ortega y Gasset (1956, p. 21): "Tenemos con nuestra vida que entender las ajenas, precisamente en lo que tienen de distintas y extrañas a la nuestra", se puede decir que el punto de arranque es histórico-generacional, lo que en clave orteguiana, significa ver a los sujetos del pasado como interlocutores válidos de los sujetos del presente y viceversa porque: "nuestra vida es el intérprete universal". "Mientras del prójimo espero siempre, últimamente, que llegue a ser como yo, frente al antiguo no tengo más remedio que asemejarme imaginariamente a él, hacerme el otro" (Ortega y Gasset, 1956, p. 22).

Visto que los cinco hablantes coinciden en que por la comunicación nos relacionamos con el entorno y construimos la convivencia y la coexistencia, una filosofía del lenguaje se convierte en el segundo punto de partida. No obstante, estos dos puntos de partida no son suficientes, ya que nuestros hablantes tienen otra coincidencia histórico-generacional: el valor perseguido. Porque los dialogantes persiguen el mismo valor básico la "vida buena" para todo hombre. En esta investigación, Tomás ya no sólo se acerca a los hombres del presente, como el que usó el mismo término, sino también como el hablante que es capaz de comunicar y mover al otro a replicar o actuar. Sus términos son significativos para sus interlocutores y los de ellos también para él. 
En esta investigación se pretende poner a los hablantes en la situación del primer paso prudencial; según Tomás de Aquino: "memoria de las experiencias adquiridas" y de asegurar, a través de esto, el segundo paso que define la prudencia: el "buen consejo" de los que saben más. Esto no significa que entre los hablantes existan relaciones jerárquicas o subordinantes, sino que todos los hablantes son "autoridades" en el tema, pero que cada uno está dispuesto a aceptar lo que los otros pueden aportar como nuevo, dada la distinta experiencia y formación de los interlocutores. Por momentos, Chomsky puede saber más que el resto desde determinado punto de vista; o más bien Rawls; o más bien el gran medieval, que acostumbraba a transmitir en su discurso el saber acumulado de griegos, romanos, musulmanes $y$, por supuesto, la muy decantada sabiduría cristiana de 1.300 años.

Se encuentra, entonces, un triple punto de partida: histórico-generacional/comunicación/ "vida buena". En consecuencia, se puso como objetivo encontrar en todos su idea personal de la comunicación; Rawls parte de la idea de que no es posible asegurar, en la situación inicial, la elección correcta de los principios de justicia sin un procedimiento de argumentación. Es con un orden lexicográfico, el "diccionario" de una cultura, con el que se puede determinar la jerarquía de los principios de justicia y sus derivaciones. Se trata de algo así como una especie de "constructivismo político", como él lo llamó. Por su parte, A Bobbio le interesa investigar la estructura propia de los lenguajes jurídicos y políticos. Chomsky es considerado la cabeza de la lingüística y el teórico de la política, quien, haciendo crítica del discurso político desde la idea de gramática universal, pretende revelar en las gramáticas particulares la voluntad de poder y la intención de dominación. Alexy pretende demostrar, con su argumentación jurídica -enmarcada en una teoría del Estado- que hay una estructura lingüística de la razón técnica que se debe orientar por una estructura lingüística de la razón práctica.
Por último, Tomás parte de este supuesto:

Si el hombre fuese por naturaleza animal solitario, le bastaría las pasiones del alma [...] pero como es animal naturalmente político y social, fue preciso que las concepciones de un hombre fuesen conocidas por los otros, lo cual se realiza mediante la voz; y por eso fue necesario que existieran voces significativas, para que los hombres pudiesen convivir entre sí (Aquino de, Sobre el Peri Hermeneias, L. I, lec. 2).

\section{ALGUNOS DIÁLOGOS}

\section{El sentido de lo político en Norberto Bobbio y en Tomás de Aquino}

Para Bobbio, la determinación del sentido de lo político constituye la tarea más importante de la filosofía política². En la realización de dicha labor, describe la política como la esfera de las relaciones humanas en la que se ejerce "voluntad de poder"; por lo tanto, lo político toca con la esfera de las acciones que tienen alguna relación directa o indirecta con la conquista y el ejercicio del poder último (supremo o soberano) sobre una comunidad de individuos en un territorio. De allí que la relación

2 Bobbio considera que hoy en día la función más útil de la filosofía política es analizar los conceptos políticos fundamentales, comenzando precisamente por el de política. Más útil, porque son los mismos conceptos usados por los historiadores políticos, por los historiadores de las doctrinas políticas, por los politólogos, por los sociólogos de la política, pero, con frecuencia, sin prestar cuidado en la identificación de su significado, o de sus múltiples significados. En ese esfuerzo analítico, distingue cuatro significados diferentes o "formas" de "filosofía política": la primera corresponde a la manera más tradicional y coherente de entender la filosofía política que consiste en la descripción, proyección y teorización de la república óptima o, si se quiere, como la construcción de un modelo ideal de Estado, fundado en algunos postulados éticos últimos, sin preocuparnos de cuándo y cómo pueda ser efectiva y totalmente realizado. Una segunda forma de comprender la filosofía política es considerarla como la búsqueda del fundamento último del poder, que permite responder a las preguntas ¿a quién debo obedecer?, y zipor qué?; pero también por filosofía política también se puede entender la determinación del concepto general de "política", como actividad autónoma, manera o forma del espíritu que tiene sus características peculiares que la distinguen, así de la ética como de la economía, del derecho o la religión; finalmente, también la filosofía política se concibe como discurso crítico, entendido sobre supuestos, condiciones de verdad, pretensiones de objetividad de la ciencia política. (Fernández Santillán, 1996, p. 61). 
entre lo político y el poder sea inescindible, entendiendo el poder como la capacidad de un sujeto de influir, condicionar y determinar el comportamiento de otro individuo (Fernández Santillán, 1996, p. 463 y p. 135). De esta manera, la relación política es una de las muchas formas de relación de poder existentes entre los hombres.

Esta relación entre la política y el poder lleva a Bobbio a emprender un análisis sobre las diversas formas de poder, aludiendo que se han adoptado varios criterios en la historia para distinguir dichas formas. Expresamente, cita a Aristóteles, quien asume el criterio de las personas, para quienes se ejerce el poder para bien; por ejemplo: el paternal, en provecho de los hijos; el patronal, para ventaja del amo, y el político, para el bien de la polis. Sin embargo, para Bobbio, esta distribución clásica del poder político con respecto al poder paternal y al despótico no permite ubicar y delimitar el real campo de la política, porque caracteriza la esfera política como debería ser y no como es.

A raíz de esta insuficiencia, se derivaron los diversos intentos de definir la política mediante un nuevo criterio, el del fin. Pero, según Bobbio, también este criterio deviene inadecuado en razón de que el fin de la acción política es, en sí mismo, algo vago. Estas tendencias teleológicas ponen como fin de la acción política el bien común, el cual es entendido como bien de la comunidad diferente del bien personal de los individuos que la componen.

La distinción entre bien común y bien de los individuos es la que, entre otras cosas, desde Aristóteles, se emplea para distinguir las formas de gobierno buenas de las malas: el buen gobierno es el que se preocupa del bien común; el malo se inclina al bien propio, se vale del poder para satisfacer intereses personales. Sin embargo, precisamente porque esta distinción es útil para diferenciar las formas buenas de gobierno de las malas, Bobbio considera que no sirve de igual modo para caracterizar la política en cuanto tal y, por ende, en esta consideración de la política también se confunde el juicio de valor, con el juicio de hecho (Fernández Santillán, 1996, p. 137).

En consecuencia, para el iusteórico italiano, en una clara manifestación de su herencia analítica, el "concepto" de bien común, como fin que se debe buscar mediante la acción política y como concepto clave de su definición, resulta falto de claridad e indeterminación, en razón de la variedad de significados que históricamente se le han dado y que han sido aceptados.

Por las razones expuestas, Bobbio considera que el criterio más adecuado para distinguir el poder político de otras formas de poder, y, por consiguiente, para delimitar el campo de la política y de las acciones correspondientes, es el que atiende a los medios de los cuales las diferentes formas de poder se sirven para obtener los efectos deseados. En ese sentido, sostiene que el medio del que se sirve el poder político -en última instancia-, a diferencia del económico y del ideológico, es la fuerza ${ }^{3}$.

Bobbio es de la idea que sin la existencia de ese poder soberano, al que le está permitido el uso de la fuerza física para alcanzar los efectos deseados, no sería posible contar con un instrumento idóneo y eficaz para resolver los conflictos que se dan en una sociedad; conflicto que, de no solucionarse, acarrearían la disgregación interna de la comunidad política. Por eso, la expresión más distintiva de la política es la guerra, en cuanto es la expresión máxima de la fuerza como medio para solucionar los conflictos.

En este proceso de discernimiento sobre lo específico de la política, Bobbio distingue entre la acción

3 En cuanto el poder político, éste se distingue por el uso de la fuerza, se erige como el poder supremo o soberano, cuya posesión distingue en toda sociedad organizada a la clase dominante; además, Bobbio es de la idea de que sólo la utilización de la fuerza física sirve para impedir la insubordinación y para subyugar la desobediencia. (Fernández Santillán, 1996, p. 139). 
social y la acción política. En ese sentido, afirma que, aunque toda acción política es una acción social en el doble sentido de evento interindividual y de acontecimiento grupal, no toda acción social es política. Lo social abarca lo político y, en consecuencia, la política es apenas una de las grandes categorías en las que se divide el universo social. A su vez, esta distinción le permite distinguir los tres tipos de poder que se presentan en el entramado social: el poder político, el poder económico y el poder ideológico, que constituyen esferas vecinas, aunque con fronteras flexibles y que han llevado a su superposición, según las diversas épocas de la historia: lo ideológico sobre lo político y lo económico sobre lo político o viceversa.

Por su parte, en el pensamiento de Santo Tomás se encuentra no sólo una ciencia política, sino también toda una filosofía de lo político. Lo analógico de su discurso permite ver cómo, de manera magistral, hace confluir reflexiones metafísicas, éticas y antropológicas, con otras que, referidas al poder, y a quién debe detentarlo, tiene que ver más con lo que actualmente se denomina "ciencia política". Por lo anterior, al referir a la filosofía política, Tomás se concentra, como objeto de estudio, no sólo en el sentido de lo político -como lo hace Bobbio-, sino que también busca la esencia de lo que es la sociedad política, su fundamentación, su finalidad y su organización.

El realismo de Santo Tomás, aplicado el estudio de lo político, lo lleva a insertar dicho estudio en el marco general de su filosofía de las cosas humanas, que no es otra cosa que la filosofía moral. A diferencia de las cosas naturales, cuyo conocimiento es especulativo, la política, en cuanto ciencia humana, es especulativa y práctica u operativa, a la vez. Por eso, para Tomás de Aquino, la constitución de la comunidad civil también es una obra por realizar "según los principios del orden natural". De ahí que, como asiento sobre el que reposan todas sus reflexiones sobre la política, se encuentren bases metafísicas, pues la metafísica es la "ciencia arquitectónica por excelencia". Las consecuencias propiamente políticas de estas consideraciones generales sobre los dos grandes tipos de conocimiento humano, el especulativo y el práctico, son, en primer lugar, que la comunidad civil, sujeto del orden político, no se presenta a nosotros ni como un simple fenómeno físico (un hecho natural), ni como un puro efecto de la voluntad humana. Eso implica que la acción política se debe ejercitar con fundamento en unos principios que no pueden ser desconocidos.

Todas estas reflexiones del Aquinate sobre la política -su fundamentación y su telos-, a diferencia de lo que sucede con su filosofía sobre la ley y la justicia, no se encuentran condensadas en un tratado sistemático, sino que se encuentran dispersas en la magna obra de este egregio pensador medieval, por ende, han tenido que ser objeto de recopilación y de sistematización ${ }^{4}$. Filósofos, como Gabriel Chalmeta y Eustaquio Galán, entre otros, se han esforzado en esta labor y han visto en el pensamiento político desarrollado por de Aquino es una filosofía política que contiene principios y propuestas válidos para la solución de los problemas prácticos de la sociedad actual (Chalmeta, 2002, p. 67).

A diferencia de lo planteado por Bobbio, para Tomás de Aquino la tarea de la filosofía política no se puede reducir a la determinación del sentido de lo político. Si se atiende a ese principio hermenéutico según el cual cada uno de los textos del Aquinate ha de ser leído a la luz del conjunto de todos los demás -esto en razón de que él escribió la mayoría de sus obras en muy corto tiempo-, se considera que el hecho de que partió de la experiencia político-jurídica de su tiempo y también bebió del hontanar de sabiduría contenida en el

4 Las principales obras de filosofía política de Tomás fueron escritas después de 1265. Ellas son: el De Regno; el Comentario a la Política -que escribió hasta el libro III, lección 6-; el Comentario a la Ética a Nicómaco; y la segunda parte de la Summa theologiae. 
pensamiento aristotélico y agustino, todo lo cual le llevó a plantear una filosofía política absolutamente ligada a presupuestos ético-antropológicos, con una sólida estructura teleológica de fondo: la consecución del bien común, el logro de la "vida buena" para cada uno de los ciudadanos.

En la filosofía política de Santo Tomás se encuentra una conmistión muy particular de aristotelismo y agustinismo. Lo anterior indica que Bobbio se distancia de Tomás de Aquino en la concepción de lo que es fundamental para la filosofía política. Como se refirió anteriormente, Bobbio es un crítico de estas posturas teleológicas y de la noción de bien común, a la que considera indeterminada. No obstante, en el caso de Santo Tomás -quien es teleológico en su concepción de la sociedad y la política- esa crítica es infundamentada, porque su concepto de bien común está lleno de contenido material, es decir, se trata de la suficiencia de bienes materiales y espirituales para la comunidad, así como de la maximización del bien, de la perfección o felicidad que es propia del hombre virtuoso y del hombre que tiene lo suficiente materialmente para vivir dignamente. Es pertinente recordar que de la fuente agustina, Tomás recibió, además del "contractualismo", la concepción cristiana de la dignidad humana: del hombre que es imagen de Dios, que se presenta frente a las acciones de los otros y de la sociedad política como un absoluto moral (Chalmeta, 2002, p. 92) y que, a su vez, debe contribuir al bien común mediante la vivencia de la justicia.

Según Tomás, al Estado le corresponde velar porque esa suficiencia de bienes sea una realidad material, para lo cual cuenta con el poder represivo, que permite el uso de la fuerza al que alude Bobbio. Por esto, a diferencia de lo planteado por el iusteórico turinez, para de Aquino lo más importante y específico de la política no es el medio para alcanzar el fin, sino el fin mismo. Eso no significa que los medios no sean importantes; a la postre, Santo Tomás pone especial acento en la ley como el medio más expedito para el logro del bien común, especialmente, si es aplicada a los jóvenes que atienden más a la necesidad que a la razón y a los castigos que a la bondad. Sin embargo, siguiendo a Agustín que en De libero arbitrio, afirma que: "es justo que la ley hecha para gobernar la ciudad permita y deje sin castigar muchas acciones que son, sin embargo, condenadas por la ley divina" (San Agustín, De libero arbitrio, I, 5, 13). Tomás considera que la ley no está para reprimir todos los vicios, sino aquéllos que son más insalubres para la vida social, como lo sería la injusticia, pues, como bien lo dice Agustín de Hipona, "un gobierno sin justicia no es otra cosa que una banda de ladrones a gran escala" (San Agustín, La ciudad de Dios, IV, 4, 4.). La justicia para Santo Tomás constituye el valor más importante, integrador de su noción de bien común político, el cual constituye, a su vez, la "bóveda de su concepción política” (Chalmeta, 2002, p. 30).

En lo atinente a la distinción que hace Bobbio con respecto a la acción social y a la acción política, se pueden observar coincidencias con Santo Tomás, en el sentido de que ven lo político dentro de lo social. Para Santo Tomás el fundamento de la existencia del Estado está en la misma naturaleza social, racional y libre del hombre; naturaleza que exige una autoridad encargada de procurar el bien común, la cual, destacada por su virtud y su saber, se ponga a la cabeza de sus semejantes, dirigiéndolos, en una actitud de servicio. Como en Bobbio, en Tomás de Aquino la acción social cobija a la acción política. El ser social y político del humano constituyen para el Aquinate un modo de existencia propio del hombre, al punto que si alguno no se siente inclinado por naturaleza a la unión y convivencia con sus semejantes, no tendría una naturaleza auténticamente humana.

Finalmente, es preciso anotar que la filosofía política Tomás de Aquino es integradora y, por lo tanto -tal como lo hace también N. Bobbio-, reconoce las cercanías entre lo económico y lo político, y también considera la preocupación por el mundo 
de la política, como análoga a la preocupación por el mundo de la economía. Sin embargo, es necesario precisar que la filosofía política tomasiana no es connivente con ningún tipo de esos reduccionismos en los que se incurre actualmente como producto del afán especializador de la ciencia moderna. Para Santo Tomás, política y economía, sin perder su especificidad, caminan de la mano para el logro del fin de la sociedad política, esto es, el bien común. No sobra recordar que Tomás de Aquino insiste en la idea de que la virtud hace se conforme con lo suficiente -con la suficiencia de bienes materiales y espirituales que integran el bien común-, por eso, la pecuniativa nummularia es vituperable, en cuanto tiene un desmedido afán de lucro (Beuchot, 1997, p. 80).

\section{The Law of People, de J. Rawls y el Ius Gentium, de Tomás de Aquino: la justicia y su aplicación a las relaciones internacionales}

La teoría de la justicia de Rawls se extiende al plano de las relaciones internacionales entre los Estados, en las cuales, según el filósofo de Baltimore, análogamente a lo que acontece en el plano local, hay unos principios producto de un acuerdo inicial, que deben ser respetados; estos principios son: el de igualdad de las naciones, el del derecho de defensa propia para repeler un ataque, el del derecho a aliarse para la defensa, el de respeto a los tratados, etc. A continuación hacemos referencia a la manera como el filósofo norteamericano hace la extensión de las ideas generales de la justicia como imparcialidad, a las relaciones entre las naciones, así como a la posición tomasiana sobre el particular, contenida, especialmente, en su concepción sobre el Ius Gentium.

En el texto de la Teoría de la Justicia, Rawls plantea la posibilidad de extender las ideas generales de la justicia como imparcialidad a las relaciones entre las naciones. En este texto también hace una corta alusión a uno de los temas que tiene que ver con esas relaciones entre los pueblos: la guerra justa.
Su reflexión se dirige a los límites que, en lo que se refiere a medios, deben ser respetados por los Estados al ejecutar una guerra. Sostiene que como el objeto de la guerra es alcanzar una paz justa, los medios empleados en ella no deben destruir la posibilidad de la paz o alentar un desprecio a la vida humana que ponga en peligro nuestra seguridad y la de los demás.

No obstante, la aplicación plena de su teoría de la justicia, como equidad a las relaciones internacionales, se encuentra en su libro El derecho de gentes (Rawls, 2001), texto en el que propone las bases de lo que denomina "una utopía realista" -la de la conformación de la sociedad de los pueblos- en el orden de las relaciones internacionales, sustentada en los principios liberales. La idea planteada por Rawls es que todos los pueblos se vuelvan liberales, o por lo menos, decentes.

Lo anterior es la utopía realista; "utopía", porque es un deseo de superar los límites de la sociedad política práctica; y "realista", porque Rawls considera que es posible alcanzar la paz y la justicia entre los pueblos, esto es, lograr la conformación de una "sociedad de los pueblos" (Rawls, 2001, p. 15). Así lo refiere:

[...] la idea de utopía realista nos reconcilia con nuestro mundo social al enseñarnos que es posible una democracia constitucional razonablemente justa como miembro de una sociedad de los pueblos razonablemente justa [...] Con todo, la posibilidad de dicho orden social y político se puede considerar irrelevante mientras no se convierta en realidad [a lo cual agrega seguidamente] [...] si bien la realización no carece de importancia, creo que la posibilidad misma de dicho orden puede reconciliarnos con el mundo social. La posibilidad no es puramente lógica sino que guarda relación con las tendencias e inclinaciones profundas del mundo social. Pues mientras creamos por buenas razones que es posible un orden político y social autosuficiente y razonablemente justo, en lo interno y en lo externo podemos 
esperar de manera razonable que nosotros u otros, en algún momento y en algún lugar, lo alcanzaremos (Rawls, 2001, p. 150).

La realización de esta utopía trae como consecuencias la eliminación de problemas de orden internacional -como los de la guerra injusta-, la inmigración y la creación de armas de destrucción masiva. Pero también dicha utopía busca superar las desigualdades sociales, la discriminación que sufren ciertos grupos -especialmente las mujeres- y la falta de respeto por la libertad de conciencia, religiosa y política. El "law of peoples" es una extensión de la concepción liberal de la justicia doméstica a la sociedad de los pueblos, "buscando la plena realización de las libertades de los ciudadanos" (Rawls, 2001, p. 20).

Es necesario tener en cuenta que la primera posición original es la de la sociedad doméstica, sin embargo, Rawls plantea que para la consecución de la utopía realista se debe pensar en la idea de una segunda posición original, que considera como contratante, ya no a los ciudadanos, sino a los pueblos ${ }^{5}$. Esa "segunda situación inicial" es bastante similar a la primera: "Las diferencias no radican en el uso del modelo de representación sino en la adaptación que se ha de hacer de él, según los agentes y los temas de que se trate" (Rawls, 2001, p. 20). Asimismo, estas diferencias buscan consensuar los contratantes en esta segunda circunstancia, son los términos que regirán, conforme a acuerdos justos, las relaciones de colaboración entre los pueblos.

Las siguientes son las características que el mismo Rawls establece para describir dicha situación inicial para los pueblos:

5 Rawls es enfático en afirmar que los pueblos, y no necesariamente sus gobiernos, son los que deben tener en consideración la formulación estas bases. La razón fundamental de esto radica en no siempre los Estados representan adecuadamente los intereses de los pueblos que gobiernan, por consiguiente, pueden buscar más sus intereses personales constituyendo, incluso, serias amenazas tanto para los derechos de sus habitantes como para con otros pueblos.
- Pueblos razonable y justamente situados como libres e iguales;

- $\quad$ Representados como racionales;

- Sus representantes deliberan sobre el contenido del derecho de gentes;

- Sus deliberaciones discurren según las razones correctas, restringidas por un velo de ignorancia ;

- La selección de los principios se basa en los intereses fundamentales del pueblo, en este caso de acuerdo con una concepción liberal de justicia, ya escogido en la primera posición original (Rawls, 2001, p. 46).

Es necesario recordar que esta concepción liberal de la justicia es la de la justicia como equidad, fundamentada en los principios de igual-libertad, igualdad de oportunidades y diferencia. Además, a ello se une el respeto de cada pueblo por su propia identidad -fundada en su historia común-, tanto como la preocupación por su seguridad y su integridad territorial, por lo que exigirían de los demás ese respeto. Los principios acordados en la segunda posición original han de establecer relaciones pacíficas y duraderas de colaboración, sustentadas en la condición razonable y racional de cada pueblo. Dicha condición "se expresa [...] en su disponibilidad para ofrecer justos términos de cooperación social y política a otros pueblos" (Rawls, 2001, p. 48).

De la misma manera que sucede en la primera posición original, la igual-libertad -ya no de los ciudadanos, sino de los pueblos- y la limitación del poder de los Estados frente a ella se constituyen en el principio prioritario del acuerdo, el cual está concretado en la prohibición expresa, salvo

6 Como en la primera posición original, en esta segunda el velo de ignorancia impide a los representantes de los pueblos conocer su situación particular, con sus ventajas o desventajas presentes o futuras, de tal modo que los contratantes no puedan anteponerlas para efectos de pactar los principios. 
causales fundadas en el respeto de estas mismas libertades, de la intervención de un Estado en los asuntos internos de otro; del mismo modo, prohíbe la declaración de la guerra agresiva por intereses materiales o expansionistas. También aparecen claramente los principios de igualdad y diferencia entre los pueblos, que se manifiestan y materializan en el deber de asistencia entre ellos.

Ahora bien, ¿qué sucede con los pueblos no liberales? ¡Sería inconcebible pensar en un Rawls, quien, habiéndose manifestado en la Teoría de la Justicia tan abierto al pluralismo y a la tolerancia, al respeto por las libertades y por las diferentes concepciones de lo que es bueno, ahora apareciera exigiendo a todos los pueblos del mundo volverse liberales! En rigor de verdad, la segunda posición original, si bien es una extensión de las formas de organización liberales, no preconiza una forma única de organización de los pueblos. La pretensión de universalidad, o al menos de generalidad, del Ius Gentium de Rawls, sólo se puede justificar en la medida en que éstos sean capaces de acoger como miembros del sistema de colaboración también a pueblos no liberales (Rawls, 2001, p. 75).

Todo esto se puede dar dentro de los márgenes razonables de tolerancia definidos a partir del respeto por los principios establecidos por el derecho de gentes. Si los pueblos no respetan esos principios, especialmente los que tienen que ver con la no agresión a los Derechos Humanos y el respeto por la libertad, no podrá haber tolerancia porque, "no puede haber tolerancia frente a la intolerancia", como lo invocara G. Radbruch, pasada la primera cincuentena del siglo pasado.

Según Rawls, sólo los pueblos decentes pueden ser considerados como potenciales miembros de una sociedad de los pueblos justa. No obstante, la descripción que hace el filósofo norteamerciano con respecto a lo que es un pueblo decente es ésta:
[...] una sociedad decente no es agresiva y sólo libra la guerra en defensa propia. Tiene una idea de la justicia como bien común que asigna derechos humanos a todos sus miembros; su estructura básica incluye una jerarquía consultiva decente que protege éstos y otros derechos, y que garantiza que todos los grupos de la sociedad estén decentemente representados por cuerpos elegidos en el sistema de consulta. Finalmente, debe haber una creencia sincera y no irrazonable, de parte de los jueces y otros funcionarios que administran el sistema jurídico, en que la ley está orientada en la práctica por una idea de la justicia como bien común (Rawls, 2001, p. 103).

Estos pueblos, junto a los liberales, son capaces de hacer acuerdos procedimentales que regulen sus relaciones y les permitan beneficiarse de las relaciones recíprocas, a la vez que proporcionan un marco regulatorio con los pueblos que no están bien ordenados conforme a los cánones de la decencia política. Sin embargo, la existencia de pueblos que no están bien ordenados constituye una permanente amenaza a la adecuada estabilidad de los demás pueblos. Así se abre, entre otras de seria importancia, las cuestiones con respecto a bajo qué causales y hasta dónde los pueblos bien ordenados pueden intervenir en los asuntos de otros pueblos sin violar los principios del derecho de gentes. Es entonces cuando aparece el tema de los Derechos Humanos.

El respeto por los Derechos Humanos constituye el límite de la tolerancia y del pluralismo entre los pueblos. Al respecto Rawls dice que:

[...] los derechos humanos respetados por los regímenes liberales y jerárquicos deben ser considerados como derechos universales en el siguiente sentido: son intrínsecos al derecho de gentes y tienen un efecto político y moral, aunque no se cumplan en cada lugar. En otras palabras, su fuerza política y moral se extiende a todas las sociedades y obliga a todos los pueblos, incluidos los estados criminales o proscritos (Rawls, 2001, p. 95). 
Por ello, stricto sensu, la defensa de los derechos humanos es la única causa que puede justificar la intervención de otros pueblos ${ }^{7}$. Su defensa, desde la perspectiva del derecho de gentes, obliga moralmente a las sociedades bien ordenadas a cautelarlos y constituye el único motivo moralmente justificable para una intervención, inclusive armada, en los asuntos internos de otro pueblo.

Por su parte, Tomás de Aquino, además de recibir el gran legado del "Filósofo" -así llamaba a Aristóteles-, quien con su realismo inspiró una buena parte de sus reflexiones filosóficas, en lo concerniente al Derecho y la justicia -y en éstos el Ius Gentium-, deja ver el profundo estudio que hizo del derecho romano, especialmente de Ulpiano, a quien denominaba "El Jurista", así como de Isidoro de Sevilla ${ }^{8}$. Con base en estas fuentes, Santo Tomás dedica la cuestión 57 de la Secunda Secundae, artículo tercero, para tratar de resolver la cuestión con respecto a si existe identidad entre el derecho natural y el derecho de gentes. Con fundamento en lo estudiado por sus predecesores (Gayo, Ulpiano e Isidoro), Santo Tomás enseña que el derecho de gentes no se reduce al natural, sino que es parte de él. Para poder comprender en qué sentido habla de ese "ser parte" del derecho natural, es preciso mencionar el artículo segundo de la misma cuestión 57, en el que explica lo que se entiende por "justo natural" (derecho natural).

7 Desde la perspectiva rawlsiana, los intereses de los Estados no constituyen en sí mismos motivos legítimos de intervención en otros pueblos. Esos intereses no siempre satisfacen las condiciones de razonabilidad implícitas, como de hecho acontece con los Estados más poderosos, que se aprovechan de los más débiles.

8 Ulpiano divide el Derecho en público y privado, y luego, subdivide, a su vez, a este último en tres: el derecho natural, el de gentes y el civil. Ulpiano consideraba que el derecho de gentes era el usado por los pueblos humanos y difería del natural, ya que éste es común a los hombres y a los animales, mientras que aquél sólo rige a los hombres. Por su parte, Isidoro de Sevilla manejó como noción del lus Gentium, la de un orden jurídico cuya materia es el derecho entre los pueblos, es decir, algo cercano al actual derecho internacional público, idea que más tarde retomaría Francisco de Vitoria en sus reelecciones "De indis", en las cuales habla del Ius Gentium como el "ius inter gentes".
Para el Aquinate existen prescripciones sobre modos de comportamiento basados en una naturaleza estable del hombre, que no son producto de la discrecionalidad humana y que se fundamentan en esas inclinaciones propias de la naturaleza humana y cuyos fines la razón práctica reconoce como buenos y los presenta a la voluntad para que los siga; es a lo que llama "ley natural" (de Aquino, ST., II-II, 57, 2), sobre la cual ya se ha hecho referencia reiteradamente en el curso de este diálogo. Esa ley natural afecta la totalidad de la vida moral del hombre y, por eso, tiene que ver con todas las virtudes éticas. Cuando ella se dirige al orden de relaciones con el otro, la virtud específica que exige es la justicia, con lo que se entra en el campo del ius naturale, del cual es título.

Tomás de Aquino enseña que lo justo natural o derecho natural es aquello que, por naturaleza, es adecuado a otro; adecuación que puede tener lugar de dos maneras, en razón del modo en que puede ser considerada la relación: por una parte, de manera absoluta, que se da a partir de la captación que hace la razón de las estructuras naturales de las cosas y de las relaciones que surgen en torno a ellas; por otra, está la que determina lo justo natural con base en las consecuencias que se siguen del modo y la forma de la relación. Para medir esas consecuencias se necesita de la racionalidad; por eso, sólo el hombre en cuanto dotado por la naturaleza de razón, establece un orden y eso, es natural para él. Es en ese sentido que se afirma que el derecho natural es aquello que se adecua al hombre. En este segundo sentido, el derecho natural es la ordenación de las relaciones entre cosas y personas, reguladas por la razón humana.

Cuando Santo Tomás habla del Ius Gentium, como una forma de derecho natural, lo refiere directamente a lo natural en el segundo sentido, es decir, en relación con las consecuencias o utilidad. De esta manera, el derecho de gentes en Santo Tomás es, al mismo tiempo, natural y positivo, ya que es producto de la razón humana, la cual puede 
llevar a establecer pactos o convenios -sobre los que está montada toda la teoría de la justicia de Rawls. Sin embargo, hay que hacer claridad en el sentido de que aunque Rawls y Tomás coinciden en la necesidad de que exista un orden justo que sea estable, tanto a nivel doméstico, como a nivel internacional, Rawls deja todo en manos del consenso -conceptos como los de "segunda posición original", "sociedad de los pueblos, término muy clásico", y "utopía realista", así lo demuestran. En contraste, Tomás de Aquino plantea que el camino para la consecución de ese orden justo y estable es imposible con el desconocimiento de la ley natural y del derecho natural absoluto, los cuales se basan en la estructura del ser humano $y$, por ende, no dependen totalmente del ser humano -así sea consensuando-, pues, para Santo Tomás, racionalidad no puede ser sinónimo de arbitrariedad.

Rawls, como buen heredero de la filosofía racionalista, pone a la razón y a la voluntad humana como las únicas fuentes de Derecho. Con esto, la oportuna y progresiva apreciación y determinación de la razón humana y la correspondiente aceptación de la voluntad humana son para él la principal fuente del Derecho. De esta manera la ley natural y el derecho natural quedan sustituidos por un derecho positivo, el cual, por ser acordado, tiene un carácter superior.

Por lo expuesto, se puede observar cómo Tomás de Aquino toma distancia con respecto a esa concepción clásica-romana, en la cual el Ius Gentium se oponía al ius civile, por ser el derecho aplicable a las relaciones jurídicas entre cives y extranjeros. En contraposición, recogió la tradición posclásica que lo concentró en un derecho de toda la humanidad, que rige el ámbito de las relaciones entre sociedades políticamente organizadas, cuyo fin es el bonum commune.

En cuanto a la guerra justa (ius ad bellum), este aspecto es específicamente abordado por Rawls, quien la legitimó frente a los pueblos proscritos ("indecentes") que violan los Derechos Humanos y amenazan la propia seguridad. Santo Tomás también la abordó, aunque también enfatizó en la guerra defensiva, pero sin calificar de proscrito a ningún pueblo, o de "indecente", pero sí buscó el mínimo daño posible, es decir, evitando la crueldad y teniendo la intención de hacer retornar la paz ( ius in bello). Todo lo anterior se encuentra dentro del marco del derecho natural y del Ius Gentium, que rige lo mismo para las naciones que para la humanidad, pues son sustrato común a todos los pueblos. Quizá sea esa la idea que quiso expresar Rawls cuando afirmó que el derecho de gentes "guarda relación con las tendencias e inclinaciones profundas del mundo social".

Cuestiones como la inmigración y el control de la producción de armas de destrucción masiva fueron explícitamente analizadas por Rawls dentro de su reflexión sobre "the law of peoples", mas no por el Aquinate, debido al momento histórico en que vivió, sin embargo, se podría llegar a afirmar que, sin duda, constituirían aspectos importantes de ese Ius Gentium y sus principios generales les serían aplicables, dentro de un marco de justicia. Esos principios han sido en buena parte recogidos por el Derecho Internacional, aunque son enunciados con la terminología propia de nuestra época: libertad e igualdad de los pueblos, autodefensa, respeto por los Derechos Humanos, asistencia a otros pueblos, etc.

No se pueden pasar por alto dos cuestiones que están en correlación con el Ius Gentium: la primera, la suspicaz crítica a la que se han sometido quienes, como Santo Tomás, ven en la servidumbre (esclavitud) algo legitimado por dicho derecho. La segunda se refiere a la relación que Rawls establece entre su utopía realista y el respeto por los Derechos Humanos, como límite de la tolerancia y del respeto por el pluralismo entre los pueblos, cuya fuerza moral y política tiene que obligar, incluso, a los pueblos criminales. 
Con respecto a lo primero, es preciso enfatizar que para Santo Tomás el dominio sobre otra persona no es algo natural por vía del derecho natural absoluto, sino que la naturaleza humana es libre y racional, por lo tanto, no tiene sentido pensar en la existencia de un derecho natural de dominio de unas personas sobre otras, en ese sentido. Sin embargo, en virtud de la racionalidad que mira la utilidad, es decir, tomando lo "justo natural" en el segundo sentido, Tomás sí considera que es posible hablar de "natural", al referir la dominación de un hombre sobre otro. En consecuencia, dice que es conveniente para un hombre que sea dominado por otro más sabio y a aquél le es útil que sea dominador. Esto significa que para Santo Tomás la esclavitud no tiene fundamento en la naturaleza humana -como muchos erradamente lo sostienen-, sino en las consecuencias buenas que, por la racionalidad de dichas consecuencias -concretamente el provecho para las dos partes, debido a la mayor sabiduría del señor sobre el siervo-, se pueden derivar de ella. Entre los hombres existe una igualdad natural. Lo natural con fundamento en la racionalidad no es lo mismo que lo natural con fundamento en la naturaleza de la cosa. Los cambios sociales, políticos y económicos influyen en esa segunda percepción de lo "justo natural", pues la naturaleza de las circunstancias aquí adquiere una especial relevancia.

Para finalizar, refiriendo a la segunda cuestión planteada, es necesario dirigir la mirada al tema de los Derechos Humanos que para Rawls constituyen, sin duda alguna y más allá del procedimiento planteado, el sustrato más importante de su "the law of peoples". Sería fácil contentarse con decir que Tomás de Aquino ve en el respeto por la persona humana -como lo ve Rawls al hablar de Derechos Humanos- un elemento fundamental -quizá el más fundamental- del Derecho, en general, del derecho de gentes, en particular, y de la justicia, como tal. Eso, aunque es cierto, requiere ser profundizado, porque detrás de uno y otro discurso hay un fundamento diferente.
Las formulaciones hechas por Rawls y que refieren a los derechos del hombre, a los Derechos Humanos y que han sido acogidas por múltiples organismos internacionales, responden más al espíritu idealista del racionalismo, para quien la razón humana, como dueña absoluta de los destinos del hombre, es capaz de establecer un código de valor universal omnicomprensivo de todos los derechos necesarios para la conformación de la gran "sociedad -ordenada- de los pueblos". La fundamentación dada por Santo Tomás se sustenta en el realismo -en la metafísica- y no en el idealismo.

Hoy en día se habla en todos los espacios -académicos y no académicos- del respeto por los Derechos Humanos. Hasta la persona más humilde y menos docta, exige su respeto. Sin embargo, resulta contradictorio que se hable en todo el mundo de la garantía y protección de dichos derechos, pero, tras ello, sobrevengan consecuencias nocivas para el mismo hombre en su ser individual y social. ¿Cómo se puede hablar de protección de los Derechos Humanos si se permite la aniquilación del humano, por ejemplo, en el caso del aborto? Es un contrasentido. No se puede afirmar, como excusa, que uno es el problema jurídico de la libertad y otro el problema filosófico: la realidad es que el único problema es el respeto por el ser humano y por su dignidad, que exige ordenamientos jurídicos de los Estados y de sus intérpretes, su salvaguarda.

Erróneamente se cree que los Derechos Humanos nacieron al finalizar el siglo XVIII, cuando fueron objeto de codificación. Toda la doctrina del derecho natural constituye el antecedente de los derechos del hombre modernos. En el contenido del concepto de Ius Gentium de Santo Tomás se encuentra todo un hontanar de conocimientos con respecto a los Derechos Humanos, su fundamentación y su positivización, aspectos que, posteriormente, fueron desarrollados por la Escuela de Salamanca y que se constituyeron en el gran fanal que iluminó el respeto por la persona 
de los indígenas durante la conquista española. La concepción actual de los Derechos Humanos está impregnada de positivismo jurídico, de ahí que su contenido y alcance se dejen en manos de una racionalidad humana, la cual, inmersa en la petulancia y la autosuficiencia, se niega a mirar hacia la propia naturaleza humana por considerarla un "simple concepto metafísico".

Desde la perspectiva tomista, el ámbito del conocimiento humano se dirige hacia las cosas en su naturaleza, la cual, a su vez, nos lleva hacia su esencia, teniendo siempre un referente sensitivo, porque allí está el origen de todo conocimiento. Para el caso de los Derechos Humanos, éstos no se pueden fundamentar en otra cosa distinta que no sea la propia naturaleza humana: naturaleza corpóreo-espiritual, racional y libre, cuyo telos es la felicidad; naturaleza que muestra de manera evidente que en el hombre existen unas inclinaciones naturales básicas que no pueden ser desconocidas por ningún tipo de legislación positiva. Sólo a partir del respeto por esa realidad humana se pueden fundamentar, dándoles su verdadero sentido, los que llamamos "Derechos Humanos".

Los Derechos Humanos coinciden con los derechos naturales del hombre porque se trata de los derechos que resultan, de modo seguido, de las inclinaciones naturales del hombre. Si se atiende al orden dado por Santo Tomás en la I-II, cuestión 94 de la Summa Theologiae, al abordar el tema de la ley natural, se puede evidenciar una serie de derechos naturales del hombre en cuanto individuo, en cuanto ser social y en cuanto ser abierto a la trascendencia. De dichos derechos, derivan inmediatamente, como conclusiones racionalmente obtenidas de modo fácil, una serie de derechos humanos. Entre los Derechos Humanos que atañen a la persona individualmente considerada estarían, por ejemplo, el derecho a la vida, el derecho a la integridad corporal, el derecho a tener lo suficiente para vivir, el derecho a un proceso judicial justo, el derecho a la intimidad, etc. Para
Tomás existe un vínculo irrompible entre los Derechos Humanos y la libertad del hombre, pero una libertad correctamente entendida. Es la libertad que nos hace dueños de nosotros mismos y no la libertad de la absoluta autonomía que conduce a la irresponsabilidad y, por eso, es una libertad que es, a la vez, llamada, tarea y conquista, y que encuentra en la propia estructura natural del ser humano la primera piedra sobre la cual se ha de construir.

\section{Santo Tomás y Chomsky: lingüística- política: comunicación o incomunicación}

Si el lenguaje comunica algo a alguien. Chomsky dice al respecto:

El dualismo mente-cuerpo ya no es sostenible, porque no hay noción de cuerpo [...] Es cierto que se ha demostrado que Descartes estaba equivocado [...] Newton exorcizó la máquina, pero dejó el fantasma intacto. Fue la sustancia primera, la materia extensa, la que se disolvió en misterios. Podemos hablar inteligiblemente de fenómenos (procesos, etc.) físicos como hablamos de la verdad real y el mundo real, pero sin suponer que hay otra verdad u otro mundo (Chomsky, 2003, p. 50).

De ahí que, en sentido técnico, la teoría lingüística sea mentalísitica, ya que trata de descubrir una realidad mental subyacente en la conducta concreta (Chomsky, 1971, p. 6).

Una de las razones para estudiar el lenguaje es que resulta tentador considerar el lenguaje, en sentido tradicional, como un espejo de la mente (Chomsky, 1985, p. 4).

Una condición para que los mecanismos innatos sean activados es que exista la estimulación adecuada. Así para Descartes (1647), las ideas innatas son las que se derivan de la facultad de pensar más bien que de los objetos externos (Chomsky, 1971, p. 46).

Aplicando este enfoque racionalístico al caso especial del aprendizaje del lenguaje, Humboldt (1836) concluye que no se puede enseñar el lenguaje, sino 
sólo presentar las condiciones en las que se desarrollará espontáneamente en la mente de su propio modo. Así que la forma del lenguaje, el esquema para su gramática, nos viene en gran medida dada, aunque no se podrá usar sin la experiencia apropiada [...] aprender, para el individuo, es [...] extraer lo que está innato en la mente (Chomsky, 1985, p. 49).

Basado en este mentalismo, Chomsky argumenta que el lenguaje hace un aporte a la comunicación, pero que no se puede confundir con ella y no se puede esperar que de ella se establezca su estructura ${ }^{9}$. El lenguaje es para pensar, no para comunicar, aun cuando se pueda decir que se puede usar para comunicar algo. Como se puede observar, Chomsky parte de la física newtoniana -que se caracteriza por eliminación de la "mecánica de contacto"- y el concepto de "cuerpo" cartesiano queda en entredicho ${ }^{10}$. Si no hay cuerpo, sino sólo mente, mero cogito, qué razón tiene hablar de comunicación. La "mente" no se comunica con la exterioridad corpórea. Se podría afirmar con Chomsky que el código del lenguaje es uno y el código de la comunicación (lenguaje público) es otro. Para el primero el proceso lingüístico es la inferencia, para la segunda, la codificación-descodificación.

En la exterioridad, la comunicación procede de la inferencia (aspecto de la pragmática) y no de la descodificación (aspectos de la sintaxis y la semántica), porque la representación mental del hablante no tiene identidad con la representación mental del oyente. El lenguaje público es un lenguaje exterior

$9 \quad$ El lenguaje es un fenómeno mental. Por ello, Chomsky contrapone el lenguaje-I (interno) al lenguaje-E (externo). En Chomsky, el lenguaje-I se refiere al lenguaje interno a la mente-cerebro que no relaciona la mente con el mundo exterior. El lenguaje-E se refiere a la posibilidad de un ente externo al individuo definible, es decir, una especie de lenguaje colectivo que pueda servir para expresar, por ejemplo, la política. Chomsky no cree en la existencia de tal lenguaje-E (Nehil, 2001, p. 204). Habría mucha analogía con el verbum mentis y el verbum exterior, dos conceptos desarrollados por Tomás de Aquino en su filosofía del lenguaje ubicada en varias de sus obras.

10 En la glándula pineal cartesiana se encuentra un poder causal que permite inferir que en Descartes el alma mueve al cuerpo, lo que sirve de causa corpórea escindible (Descartes, P. A. a. 38). que depende del lenguaje-I (individual e interno). El lenguaje público no determina la existencia del lenguaje-I, porque éste es innato ${ }^{11}$. Más bien el Ienguaje-I determina la existencia del lenguaje-E (externo), porque el proceso de inferencia en la dimensión pragmática ocurre en el interior de la mente-cerebro. Además una comunicación basada en las dimensiones sintáctica y semántica de las palabras lleva a la incomunicación, pues los hablantes sin el contexto "inferido" no se entienden. La descodificación no basta.

Así, en materia de filosofía política, Chomsky considera que no hay cuerpo político definible de manera precisa, porque no hay cuerpos individuales que lo compongan también de manera concreta. Sólo hay un todo mental que es real ${ }^{12}$ : la mente individual que se expresa a través de su "espejo": el lenguaje. La política, como movimiento causal, al no tener cuerpo definido, no existe tampoco. Al ser las verdades autoevidentes, el lenguaje no quiere comunicar nada al exterior, sino al interior; es como una proyección mental en la que ella misma se explicita. El lenguaje político, entonces, es reflejo de una mentalidad individual. El lenguaje del político que encubre intenciones opresoras adolece de un defecto frente a la mente del intelectual. El intelectual comprometido con la verdad, es decir, ha inferido del contexto político

11 “[...] no cabe duda de que hoy no hay ninguna razón para tomar en serio una posición que atribuye por completo un logro humano complejo a meses (o a lo sumo años) de experiencia, en vez de atribuirlo a millones de años de evolución o a principios de organización neutral que pueden estar todavía más enraizado en leyes físicas - una posición que, además, llevaría a la conclusión de que el hombre es, aparentemente, único entre los animales por su modo de adquirir conocimiento-. Tal posición es particularmente implausible en lo que respecta al lenguaje" (Chomsky, 1971, p. 56).

12 Chomsky precisa: "Elaboramos las teorías lo mejor que podemos tomando como real lo que se postula en las mejores teorías que somos capaces de elaborar (porque no hay ningún otro concepto relevante de lo 'real'), tratando de llegar a la unificación con los estudios de otros aspectos del mundo" (Citado en: Nehil, 2001, p. 185). Una frase como la de Hegel (1968): "lo que es racional es real; y lo que es real es racional" comentando a Platón marca el momento en que la filosofía toma el rumbo del "mentalismo". Véase Prefacio de la Filosofía del Derecho. La filosofía política de Chomsky, desde nuestro punto de vista, tiene fuerte analogía con la teoría del Derecho y del Estado de Hegel. 
lo correcto, es el encargado de criticar la validez del leguaje político opresor ${ }^{13}$.

\section{Sed contra:}

2. El hombre tiene como natural el vivir en una sociedad de muchos miembros [...] 3. Además, a los otros animales la naturaleza les inculcó todo lo que es beneficioso o nocivo [...] El hombre, por el contrario, únicamente en comunidad tiene un conocimiento natural de lo necesario para su vida [...] de manera que cada uno investigue una cosa por medio de la razón [...] Esto se ve con claridad meridiana en el hecho de que es propio del hombre hablar, por medio del cual una persona puede comunicar totalmente $o$ otra sus ideas [...] Luego el hombre es el más comunicativo para otro hombre que cualquier otro animal gregario (de Aquino, RP., L. I, c. 1).

En Tomás de Aquino la premisa interpretativa es el essey, desde ella, busca explicarlo todo. Para el caso del existente humano, de Aquino precisa definir su natural sociabilidad, como elemento esencial de su ser, a partir de la indigencia en que se encuentra, es decir, necesitado, esencialmente, del otro. Pero, él no se ordena a la vida en sociedad por partes, sino todo él, en cuerpo y alma. Por lo tanto, el hombre no se puede definir ni como cuerpo ni como alma separados quedando el cogito, o más bien el cognosco, subordinado al esse. Si no tuviera indigencias o sería espíritu puro, o meramente cuerpo animal instintivo especializado (como el que nace con "garras" [de Aquino, RP., L. I, c. 1] para cazar). Mas, el hombre es "lo más perfecto en toda la naturaleza" (ST, I, 29, 3), es decir, un compuesto de alma y cuerpo. Aquélla está unida a él de manera sustancial. Esta unión sustancial entre cuerpo y alma pone al cogito necesitado del cuerpo y al cuerpo necesitado de ella en una especie de co-causalidad.

13 Si la lingüística chomskyana es "mentalista" se puede ubicar en la historia de la filosofía después de la física newtoniana, que ayuda a eliminar el estatus conceptual del problema mente-cuerpo.
La filosofía tomasiana del esse, que determina su concepción del hombre, se contrapone a la filosofía que pretende meter en el campo del cogito todos los seres. Así como contenidos de la conciencia, sólo existen en ella. En de Aquino, cuerpo y alma se realizan mutuamente comunicando, el primero, sus carencias a la segunda que lo impulsa a perfeccionarse. Con el cuerpo el alma entiende el mundo exterior porque "el cuerpo le es necesario al alma intelectiva en orden a su operación propia, que es entender" (ST., I, 84, 4) $)^{14}$. Ahora bien, no hay paridad entre el sentido y el entendimiento, porque si esto fuera así, el ser que las cosas materiales tienen fuera del alma sería inteligible en acto. Esto último permite precisar el sentido de la comunicación:

- $\quad$ Nunca es perfecta, porque lo inteligible siempre es en potencia;

- $\quad$ Si todo fuera inteligible en acto no sería necesario el ser de las cosas materiales y no se necesitarían los sentidos, pues se podrían conocer los objetos sensibles con sólo pensarlos.

Este último literal Ilevaría a la conclusión de que si se admite "ciencia natural innata" (de Aquino, ST., I, 84, 4), como en Chomsky (Descartes-Newton) ${ }^{15}$,

14 Para puntualizar sobre la imposibilidad de entender el alma mediante "especies precedentes del entendimiento", de Aquino precisa al final del artículo 4: "Y de este modo podría in ciego de nacimiento tener idea de los colores; cosa evidentemente falsa. Por consiguiente, se ha de afirmar que las especies inteligibles mediante las cuales conoce nuestra alma no emanan de formas separadas". En la solución a la primera objeción precisa que: "Las especies inteligibles [...] proceden [...] a través de las formas de las cosas sensibles y materiales, de las cuales, como dice Dionisio, obtenemos la ciencia".

15 Es preciso atar Descartes y Newton, porque en Chomsky la gramática universal se desprende de Descartes, mas -como ya se precisó- su antropología dualista es superada por la idea del cuerpo de la física newtoniana. Para un cartesiano, sin clave newtoniana, la palabra me comunica el otro: "Un 'cartesiano menor', Géraud de Cordemoy, expuso sus puntos de vista sobre el problema en un escrito cuya importancia no ha escapado a Noam Chomsky [...] Este escrito está enteramente dominado por la problemática cartesiana. Se trata en todo él, desde el principio hasta la última página, de distinguir el alma del cuerpo, es decir, de hacer ver que nada de lo que pertenece a la naturaleza de uno es de la naturaleza del otro. Estos cartesianos tienen por lo menos 
no habría comunicación alguna, porque lo comunicable ya está comunicado (= comunicación absoluta o perfecta anulación de lo otro como distinto. Habría mismidad).

Se sabe que Chomsky no caerá en el extremo de la confusión del otro en mi yo, pues su "anarquismo" lo hará ver la comunidad humana fragmentada en partículas incomunicables, cuya libertad consiste en el ejercicio pleno de su cogito ("querer y no querer"16). No obstante, tal incomunicabilidad está superada por la "Gramática Universal" (GU) que en cada individuo es "Gramática Generativa" (GG), es decir, creativa ${ }^{17}$. En Chomsky, esto asegu-

el mérito de ser perfectamente claros: 'He propuesto, en los seis discursos que han precedido a éste, el medio de conocerse; $y$ he hecho ver que no consiste en más que en discernir en sí mismo las operaciones del alma y las del cuerpo. Ahora propongo el medio de conocer a los otros; y este medio es la Palabra" (la última cursiva es mía) (Gilson, 1974, p 80).

16 Descartes responde a la pregunta: "Qué soy yo, pues? Una cosa que piensa. ¿Qué es una cosa que piensa? Es una cosa que duda, entiende, concibe, afirma, niega, quiere, no quiere y, también, imagina y siente" (MM. II.).

17 "Contrariamente a lo que se cree en general, la diversidad de las lenguas no es infinita [...] No podemos decir cualquier cosa, ni hablar de cualquier modo. Todas las lenguas se basan, en realidad, en una sola gramática universal, y la estructura de las lenguas que el hombre es capaz de hablar es limitada. ¿Por qué? Porque estamos condicionados por nuestro patrimonio genético. Nuestra biología no nos permite producir o combinar cualesquiera sonidos, ya que el lenguaje es el producto de nuestra evolución natural [...] La humanidad [...] es homogénea en su expresión lingüística, tal y como lo es en su biología. Es un hecho comprobado que todas las lenguas pueden aprenderse y traducirse a otra lengua. Ninguna dificultad de traducción es insuperable en el seno de la especie humana" (Chomsky, 1992, p. 97).

La discusión sobre la gramática universal, la podemos centrar en la vieja disputa sobre los universales. Para el nominalismo los universales no se hallan ante rem (no están antes que la cosa), como sostiene el realismo o el platonismo. No están tampoco in re (en la cosa), como sostienen el conceptualismo, el realismo moderado, o el aristotelismo. Los universales son simplemente nomina, nombres, voces, vocablos o termini, términos convencionales post rem. El nominalismo sostiene que sólo tienen existencia real los individuos particulares. El cartesianismo de Chomsky ubica los universales ante rem. Chomsky precisa: “Una estructura de la lingüística que aspira a la adecuación explicativa da razón de los universales lingüísticos y atribuye conocimiento tácito de estos universales al niño. Sugiere, pues, que el niño se enfrenta a los datos con el supuesto de que pertenecen a una lengua de un cierto tipo de antecedentes biendefinido. El problema del niño es determinar cuál de las lenguas (humanamente) posibles es la de la comunidad que la ha tocado en suerte." Lo que le permite formular la siguiente pregunta: “¿Cuáles son los supuestos iniciales con respecto a la naturaleza ra una comunicabilidad universal innata basada en el principio de igualdad de todos los seres humanos. Así, como a nivel genético, se tiene el "genoma humano", una estructura universal del ADN, lo mismo se puede decir de la gramática, que es "universal". Por ello, el intelectual, el que ha alcanzado la máxima GG, debe tener un papel clave en la sociedad: decir la verdad a toda costa y revelar la falsedad del opresor.

Con Tomás-Noam, el lenguaje efectivamente tiene como función principal conocer, es decir, estar al servicio del vermum mentis, y que una de sus posibilidades es comunicar. Por ejemplo, la visión tiene por objeto traer los colores al entendimiento y puede, entre sus posibilidades, comunicar algo. Esto quiere decir que para los dos filósofos, aunque estén en posiciones epistemológicas distintas, el lenguaje juega un papel clave para entender las estructuras mentales.

Es así como el entendimiento o la mente no tienen un órgano preciso a través del cual funcionen. Hoy en día se ata la mente con el cerebro y se hace creer que ya se tiene la respuesta de que la mente funciona con el cerebro (o en él). Esto es posible si se define el cerebro como algo corporal; éste sería el órgano mental. Sin embargo, como no se puede definir lo que es el cuerpo, icómo se puede asociar la mente con el cerebro? (Como lo hacen los lingüistas posnewtonianos). Más difícil es dilucidar el problema de si el lenguaje es como funciona la mente, es decir, su "espejo"; si la respuesta fuera positiva se estaría afirmando que fisiológicamente

del lenguaje que el niño aporta al aprendizaje lingüístico, y cuál es el detalle y especialidad del esquema innato (la definición general de "gramática") que gradualmente se hace más explícito y diferenciado a medida que el niño aprende la lengua?" (Chomsky, 1971, p. 27). En cuanto al problema de los "universales", Tomás de Aquino repetía la doctrina generalmente aceptada entre los escolásticos de la tripartición en universal ante rem, in re y post rem, pero aclarando que los universales en cuanto tales solamente están en la mente ( $p o s t$ rem), y que en la realidad sólo se dan en realizaciones individuales (in re). Hace recaer propiamente todo el peso en el universale ante rem o forma esencial que da su ser a cada substancia y que tiene su sede en la inteligencia creadora. 
el cuerpo, especialmente los órganos del habla, están hechos específicamente para el lenguaje, lo que no es probable. Ahora bien, lo que sí se puede afirmar, desde el evolucionismo, es que el lenguaje, fisiológicamente hablando, es "función añadida", que "Saca todo el partido posible de órganos y de funciones, nerviosas y musculares, que fueron producidas y se conservan para fines muy distintos que el del lenguaje" (Gilson, 1974, p. 97).

Esto confirma que el entendimiento funciona sin órgano corporal ${ }^{18}$, por lo tanto, no se puede confundir el entendimiento con el lenguaje. Lo anterior precisa que la capacidad creadora está en el entendimiento y no en el lenguaje (Gilson, 1974, p. 110). No se puede afirmar que algo que se exterioriza, que tiene cuerpo, a través del cuerpo, es la forma del entendimiento, o por lo menos un indicio de lo que es la mente y sus estructuras. Esto podría decir algo si la antropología fuera la de Tomás de Aquino.

Lo que se expresa a través de los sonidos, que Ilamamos lenguaje, requiere siempre un acto interpretativo. Este acto interno no se expresa y recae sobre la capacidad imaginativa que articula lo que está en la memoria. Por eso es que la voz "supone cierta imaginación para establecer su significado" (de Aquino, Comentario In De anima, II, 8, lect, 18. "cum imaginatione ad aliquid significandum") para establecer su sentido. Hay que descodificarla y, si es necesario, haciendo uso de la fantasía, hay que inferir su uso en la práctica en un contexto determinado.

En clave tomasiana, la razón especulativa tiene sus propios mecanismos de conocimiento y la razón práctica los suyos. Chomsky, inscrito en la tradición, trabaja la lingüística como ciencia que busca reve-

18 Gilson dice: “[...] según Tomás de Aquino y, en cierto sentido, Aristóteles, el entendimiento funciona 'sin órgano corporal'. Se piensa incluso en el alma tal como la concebían los Platónicos, y entre ellos Agustín: una substancia inmaterial 'utens corpore'" (1974). lar las estructuras de la mente-cerebro y se ubica en el ámbito epistémico de la razón especulativa. De acuerdo con Quine, se entiende como una matemática llamada "gramática universal". Pero, cuando la lingüística se asocia con la política y el discurso de la política, en el ámbito de la educación y la política será razón práctica en torno a la "gramática generativa". Sin embargo, Chomsky, como Tomás, no las separan o escinden, sino que, por el contrario, establecen relaciones entre ellas $^{19}$. Chomsky se encuentra en una ciencia que podríamos ubicar en una zona intermedia entre las dos razones: psicología cognitiva.

El profeta para Tomás, como el intelectual para Chomsky, es clave en las comunidades. La razón es que hay personas que tienen unas condiciones especiales que les permiten ver mejor que los demás. En el Tratado de la Ley, de Aquino puntualiza esta desigualdad real en la inteligencia de la verdad:

Y la verdad es de alguna manera conocida por todos, al menos en cuanto a los principios comunes de la ley natural. En lo demás, unos participan más y otros menos en el conocimiento de la verdad $\mathrm{y}$, a tenor de esto, conocen más o menos la ley eterna (ST., I-II, 93, 2).

El hecho de que Tomás y Chomsky se encuentren no significa que ellos pierdan sus identidades con respecto a la concepción que cada uno tiene del hombre: para Aquino el hombre es unidad sustancial cuerpo-alma; para Chomsky el hombre es

19 Tomás de Aquino aclara: "Así como en los actos exteriores podemos distinguir la operación y la obra, por ejemplo, la edificación y el edificio, así en las operaciones de la razón cabe distinguir también su acto, que consiste en entender y discurrir, y lo producido por este acto. Hablando de la razón especulativa, este producto es triple: primero, la definición; segundo, la enunciación tercero, el silogismo o argumentación. Ahora bien, como la razón práctica emplea, a su vez, una especie de silogismo ordenado a la operación, según dijimos arriba (q.13 a.3; q.76 a.1; q.77 a.2 ad 4), siguiendo la doctrina del Filósofo en Ethic., debemos encontrar en la misma razón práctica algo que sea respecto de la operación lo que en la razón especulativa son las proposiciones respecto de la conclusión. Y estas proposiciones universales de la razón práctica, ordenadas a la operación, son precisamente la ley, bien que sean consideradas en acto por la razón, bien que sólo se encuentren en ella de manera habitual" (ST., I-II, 90, 1, ad 2m). 
alma sin cuerpo definible. Para Tomás la génesis del conocimiento intelectivo se opone a las teorías innatistas. Chomsky es innatista. No obstante, el tomismo del Raimundiano, desde su primer trabajo investigativo, ha buscado el encuentro con el otro, porque según de Aquino, difícilmente un solo hombre puede acceder a la verdad. El ser humano necesita de los otros y de su perspectiva. Sólo así se alcanzará un principio de verdad, por lo menos más amplio que el que se tendría si se encerrará en sí mismo.

\section{Tomás de Aquino-Robert Alexy: razón práctica y principios que guíen las soluciones en casos difíciles}

\section{Si sólo la razón especulativa define las reglas de una argumentación racional en la razón práctica}

Dice Alexy que la Sala Primera del Tribunal Constitucional Federal exigió en una Resolución de "desarrollo del Derecho" que las decisiones de los jueces deben "basarse en argumentaciones racionales". Esto quiere decir que los juristas que intervienen en la decisión, directa o indirectamente, también deben argumentar racionalmente. Así, precisa Alexy, "De que sea posible una argumentación jurídica racional depende no sólo el carácter de la Jurisprudencia, sino también la legitimidad de las decisiones judiciales" (Alexy, 1989, p. 19). Esto lleva a pensar que el objeto de la investigación alexeyana es el problema de qué se debe entender por argumentación jurídica racional (Alexy, 1989, p. 19).

Alguno dirá que la exigencia del Tribunal Constitucional Federal está definiendo normativamente una práctica que ya se venía dando. ¿A caso puede haber una decisión que no se base en argumentos racionales?, ¿los argumentos jurídicos no son racionales?, ¿el procedimiento de subsunción no es racional?, ¿no se cuenta con una lógica jurídica ya decantada? Estas preguntas le surgieron a Alexy y "[...] Para ello es necesario elaborar, en primer lugar, una teoría del discurso racional que fuera más allá del estadio de los primeros conceptos. La meta de esta investigación es contribuir a dicha elaboración" (Alexy, 1989, p. 132).

Ahora bien, si "razonar" es inclinarse ante la evidencia, deducir y calcular, isólo hay una vía para definir la decisión justa?: la vía que considera que el caso se subsume en una regla, la vía que recalca que ni la elección ni la interpretación de esa regla plantean problema alguno. Si esto es así, ipor qué los ordenadores no han reemplazado a los jueces?

Alexy va a descubrir la necesidad de enriquecer el razonamiento analítico, que se ocupa de las proposiciones necesarias, con el razonamiento retórico que se basa en las opiniones. Por lo anterior, se refiere a las funciones de los hablantes: "preguntar"-"responder"; Alexy, precisa que "argumentación" y "fundamentación" son sinónimas: "Esto plantea [...] en relación con la extensión y la distribución de la carga de la argumentación o de la fundamentación" (Alexy, 1989, p. 191). Asimismo, en la nota 50 a este punto precisa: "Estas expresiones se usan en esta investigación como sinónimas" (Alexy, 1989, p. 191). La fundamentación o argumentación es dar razón para que algo sea objeto del discurso (Alexy, 1989, p. 192).

Ahora bien, si el objeto inmediato del discurso práctico es las proposiciones normativas singulares (Alexy, 1989, p. 193), ¿no cabrían también en el discurso jurídico proposiciones normativas singulares fruto de lo que es razonable? Si la repuesta a esta pregunta es negativa, quiere decir que el discurso jurídico ha hecho su tránsito al mundo del hacer, en el cual, como "técnica" (ya de coacción o de la justicia), se limita a la simple deducción formal. Todos los casos tendrán su justicia: fiat justitia, pereat mundus.

"Sed contra", Tomás de Aquino dice: "Hay que hacer constar también que tal como la razón especulativa analiza lo especulativo, la razón práctica así lo hace sobre lo operativo. Por lo tanto, es necesario que estemos dotados naturalmente de 
principios tanto especulativos como prácticos" (de Aquino, ST., I, 79, 12).

Esto indica que los principios especulativos y los prácticos son distintos. Además, los métodos de la razón especulativa y los métodos de la razón práctica también tiene que ser distintos. ¿Esto por qué es así? Porque la razón especulativa se refiere a cosas universales y la razón práctica a cosas contingentes y particulares. El método de la razón especulativa parte de verdades evidentes e indiscutibles, en las que no se requiere, como dice Tomás, "investigación” para llegar a otro conocimiento. La razón práctica opera sobre singulares, lo que le impone al juicio "investigar" y resolver lo que dicta la singularidad. Esto es algo propio de la prudencia gubernativa, por ejemplo, según el Aquino:

\begin{abstract}
Pero lo mejor en todo género de conocimiento práctico, como lo es el plan de la gobernación, consiste en que se conozcan las cosas particulares, sobre las que se centra el acto u operación de la razón práctica. Ejemplo: el mejor médico es el que no se queda en la consideración de generalidades, sino que desciende hasta los más mínimos detalles. En otros casos puede decirse lo mismo (ST., I, 103, 6).
\end{abstract}

Alexy también dice que el objeto del discurso práctico son las proposiciones normativas singulares, lo que impone conocer las cosas particulares para tomar decisiones no sólo acertadas, sino también justas.

\section{Si son necesarios unos principios para asegurar la racionalidad de la argumentación}

Según Alexy, para asegurar la racionalidad del discurso y de las conclusiones (resultados) es necesaria una base compuesta por un "sistema de reglas del discurso" $y$ "de principios del discurso". En la Teoría de la argumentación, el profesor de Kiel trata de formular "explícitamente este sistema a través de un sistema de 28 reglas". Estas reglas se extienden desde aquéllas que exigen no contradicción, claridad ligüística y verdad empírica, pasando por aquéllas que expresan la idea de universalidad, entre otras cosas, asegurando a cada uno el derecho a tomar parte en el discurso y la misma consideración en el discurso, hasta aquéllas que rigen para la argumentación consecuencialista, la ponderación y el análisis de la formación de convicciones normativas. Este sistema que pretende formular algo así como un "código de razón práctica" (en clave kantiana), no sólo completa las reglas específicas del discurso jurídico, sino que también constituye también la base para su justificación y crítica, en el marco de una justificación y crítica del sistema jurídico en su conjunto (Alexy, 1998, p. 18).

El profesor de Kiel dice que una teoría del discurso puede ser empírica, analítica o normativa. Es empírica cuando en ella se describen y explican:

- La correlación entre determinados grupos de hablantes;

- El empleo de determinados argumentos;

- $\quad$ El efecto de los argumentos; o

- Las concepciones predominantes en determinados grupos sobre la validez de los argumentos (Alexy, 1989, pp. 177-178).

Es analítica, cuando se trata de la "estructura lógica de los argumentos realmente utilizados y de los argumentos posibles" (Alexy, 1989, p. 178). Es normativa, cuando se "establecen y fundamentan criterios para la racionalidad del discurso" (Alexy, 1989 , p. 178). Esta última posibilidad la escoge Alexy para definir la teoría del discurso racional como una teoría del discurso normativa. Explica que: "Por ello, en ella se plantea el problema de cómo pueden fundamentarse las reglas del discurso racional" (Alexy, 1989, p. 178).

Alexy se apropia de la regla de Hare: "La noción de una razón [fundamento], como siempre, lleva consigo la noción de una regla que afirma que algo es una razón para alguna otra cosa" (Alexy, 1989, 
p. 194). Esto precisa el grado en que la teoría del discurso es una teoría del discurso normativa.

\section{Sed contra:}

\begin{abstract}
Por lo tanto, tampoco los principios prácticos infundidos en nosotros por naturaleza pertenecen a una potencia especial, sino a un hábito especial natural llamado sindéresis. Por eso, se dice que la sindéresis impulsa al bien y censura el mal en cuanto que por los primeros principios procedemos a la investigación, $y$, por ellos, juzgamos lo averiguado. Por lo tanto, resulta evidente que la sindéresis no es una potencia, sino un hábito natural (de Aquino, ST., I, 79, 12).
\end{abstract}

Tomás dice que en la facultad natural de juzgar hay "ciertas reglas" y "gérmenes de virtudes" verdaderos e invariables, Dichas razones invariables son los primeros principios operativos, en los que no cabe el error y son atribuidos a la razón como potencia. Por lo tanto, como quiera que las reglas invariables que rigen en los juicios son propias de la parte superior de la razón la llamada sindéresis, hábito de buscar siempre lo adecuado a nuestra naturaleza, tiene su propio objeto: el "bien". De ahí que, por ambas, esto es, por la razón y por la sindéresis, se juzga naturalmente (de Aquino, ST., $\mathrm{I}, 79,12$, ad $3 \mathrm{~m}$ ): no se confunden razón (potencia) y sindéresis (hábito).

Aparentemente es como si Alexy y Tomás de Aquino estuvieran diciendo lo mismo. Sin embargo, esto no es así, porque en el segundo el concepto de sindéresis agrega algo nuevo que determina y cualifica cualquier principio de la razón práctica: el hábito natural de hacer el bien y evitar el mal. Para Santo Tomás no bastan los primeros principios, es necesario que ellos sean encontrados en la acción operativa de la sindéresis. Es frecuente encontrar confundida la sindéresis (hábito) con la razón práctica (potencia) en algunos tomistas. Pero, como ya se vio, no son lo mismo, pero hay una interdependencia. La razón se refiere a objetos opuestos, mientras que la sindéresis se refiere simplemente al bien.
Nota: se escogieron y se resumieron los diálogos que permiten un primer acercamiento a los autores. Por limitaciones de espacio, es imposible que presentar en este artículo la totalidad de los resultados investigativos. Se promete que en los siguientes números de lusta se presentarán a la comunidad científica los diálogos que no se han incluido.

\section{REFERENCIAS}

Alexy, R. (1989). Teoría de la argumentación jurídica. Teoría del discurso racional como teoría de la fundamentación jurídica. Madrid: Centro de Estudios Constitucionales.

Alexy, R. (1998). Derecho y razón práctica. México: Fontamara.

Beuchot, M. (1997). Ética y derecho en Tomás de Aquino. México: Universidad Autónoma de México.

Chalmeta, G. (2002). La justicia política en Tomás de Aquino. Pamplona: EUNSA.

Chomsky, N. (1971). Aspectos de la Teoría de la Sintaxis. Madrid: Aguilar.

Chomsky, N. (1985). Reflexiones sobre el lenguaje. Barcelona: Planeta-Agostini.

Chomsky, N. (2003). Sobre la naturaleza y el lenguaje. Madrid: Cambridge University Press.

De Aquino, T. (1947). De Regno (edición crítica del P. Mandonnet, O.P., Introducción y notas por el Pbro. Antonio Tomás y Ballús). Buenos Aires: Poblet.

De Aquino, T. (1988). Suma Teológica (tomo I, dirigida por los Regentes de Estudios de las Provincias Dominicanas de España). Madrid: BAC.

De Aquino, T. (1989). La monarquía. Al rey de Chipre (según la edición de Laureano Robles y Ángel Chueca). Barcelona: Tecnos. 
De Aquino, T. (1989). Suma Teológica (tomo II, dirigida por los Regentes de Estudios de las Provincias Dominicanas de España). Madrid: BAC.

De Aquino, T. (1990). Suma Teológica (tomo III, dirigida por los Regentes de Estudios de las Provincias Dominicanas de España). Madrid: BAC.

De Aquino, T. (1994). Suma Teológica (tomos IV y V, dirigida por los Regentes de Estudios de las Provincias Dominicanas de España). Madrid: BAC.

De Aquino, T. (2003). De Regno. Opúsculos y cuestiones selectas (coordinación Antonio Ossuna Fernández-Largo). Madrid: BAC (Maior).

De Aquino, Tomás \& de Alvernia, Pedro. (2001). Comentario a la Política de Aristóteles (Traducción y prólogo de Ana Mallea, notas de Mallea y Celia A. Lértora). Navarra, Pamplona: EUNSA.

De Aquino, Tomás. (1989). Régimen de los Príncipes (Carlos Ignacio González, traductor). México: Porrúa (Versión que incluye los Libros adicionados por Tolomeo de Lucca).

De Aquino, Tomás. (2001). Comentario a la Ética a Nicómaco de Aristóteles ( $2^{a}$ edición, Ana Malllea, traductora; estudio preliminar y notas: Celia A. Lértora Mendoza). Navarra, Pamplona: EUNSA.
De Aquino, Tomás. (2004) Comentario a las Sentencias de Pedro Lombardo (edición preparada por Juan Cruz Cruz), I/2 (36). Navarra, Pamplona: EUNSA.

De Hipona, A. (1988). La ciudad de Dios. México: Porrúa.

Fernández S. (1996). Norberto Bobbio: el filósofo y la política, Antología. México: Fondo de Cultura Económica.

Gilson, E. (1974). Lingüística y Filosofía. Ensayo sobre las constantes filosóficas del lenguaje. Madrid: Gredos.

Hegel (1968). Filosofía del Derecho. Buenos Aires: Claridad.

Ortega y Gasset, J. (1956). Prólogo de la Historia de la Filosofía de Bréhier. Buenos Aires: Ed. Sudamericana.

Rawls, J. (2001). El derecho de gentes y "una revisión de la idea de razón pública". Barcelona: Paidós.

Smith, N. (2001). Chomsky ideas e ideales. Madrid: Cambridge University Press. 